\title{
NON-DESTRUCTIVE METALLOGRAPHY \& REPLICA METHOD FOR INSPECTION CONNECTING ROD MATERIAL AND CRACKS DETECTION
}

\author{
Zorica Kovačević ${ }^{1 *}$, Zoran Karastojković ${ }^{1 *}$, Vujadin Aleksić ${ }^{2 *}$ \\ ${ }^{1}$ Institute for Testing of Materials, Serbia Institute, Bulevar vojvode Misica 43 St., 11000 Belgrade, Serbia \\ 2 Technical College, Serbia \\ * corresponding author: e-mail: zorica.kovacevic@institutims.rs, info@visokatehnicka.edu.rs, \\ vujadin.aleksic@institutims.rs
}

\begin{abstract}
Resume
Testing of materials properties is usually a discipline for the quality assurance during manufacturing processes. In condition monitoring, certification or upgrading of existing plants and in failure analysis similar benefits from nondestructive testing of materials properties can be achieved. Another benefit from the Non-Destructive Metallography (NDM) is that the test can be made on-site. $\mathrm{NDM}$ is a well established and proven tool to help determine the integrity of generator and hydro turbine components during their life-cycle in power plant environments. On-site metallography of components makes it possible to evaluate the microstructure of materials. It allows microstructural analysis of large components that are difficult to move or not permitted to be destructively tested, enabling rapid evaluation of the material. Here are monitored the microstructural changes and crack detection in St 35 connecting rod steel after approximately 15 years in service. The paper includes a short description of the replica method as a technique for microstructural examination of components by using non-destructive testing method.
\end{abstract}

\section{Article info}

Article history:

Received 08 July 2013

Accepted 16 September 2013

Keywords:

NDM-metallography,

replica method,

microstructure changes,

connecting rod

\section{Scheme of water turbines}

Water turbines are machines that convert hydraulic energy into mechanical energy. This conversion is possible in a complex harnessing called a hydro power plant (HPP). Usually, the mechanical energy is further converted into electrical energy, in the same harnessing with the use of electrical generators. bines:

There are three basic types of hydro tur-

impulse,

reaction and

submersible propeller.

All produce clean energy or green energy - power from renewable resources.

There are low-, medium- and high-head turbines. They are also classified as having a vertical or horizontal orientation. A schematic view of a Hydro Power Station is shown in Fig. 1.

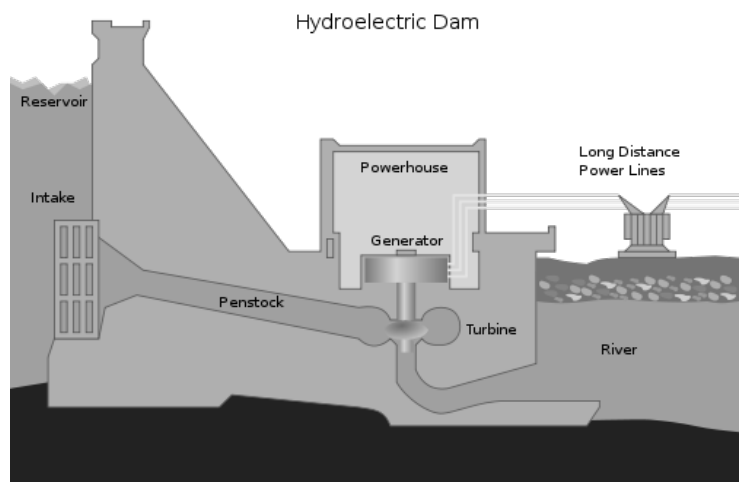

Fig.1. Schematic View of a Hydro Power Station, vertical orientated turbine. The connecting rod is between the turbine and the generator 
Such an equipment is of crucial importance for all consumers of electricity in the country.

\section{Connecting Rods forging}

For certain purposes, the machine components should be forged. The hammer exerts compressive pressure on a relatively small area. During a forging process a high degree of crystal grains refinement is obtained. The importance of finishing temperature at hot-forging as in other hot-working deformation processes is well known. A lower finishing temperature at hot forgings is sometimes caused by the presence of brittle ranges in a material. A low finishing temperature may lead to cold-working effect(s), which is indicated as a high value of the ratio of yield stress to ultimate stress, either at static or alternate loads.

For producing a long forged piece, a hotworking deformation is obvious. At forging of a large piece, a deformation is localized. A high rate of forging also permits great deformations, while the temperature drop must be kept in close limits. Hammering between flat dies may lead to causing compression stresses. At the cold edge, an additional (even tensional) stresses may be introduced by fast $\&$ irregular cooling or similar technological factors.

Medium carbon steels are available for forgings for general engineering purposes, such as: turbo-electric rotors, die blocks, gears, large hydraulic pistons, etc. In order to work those products large ingots are necessary, and a large press must be used.

\section{Experimental results}

A hydro-power generator plant is always complex in structure. A connecting rod is just a part in such a structure. A hydro-power plant, water turbines and similar parts/components of the equipment are available for analysis from many viewpoints. Here are monitored the microstructural changes that have taken place in the connecting rod material, after being in service over a quite long period of time, about 15 years.

The use of the replica method for monitoring the microstructure quality makes sense only by periodic investigation and comparison of the results with those previously obtained.
At the moment of forging production of a new part it is clear that all the consequences that may arise from the servicing conditions are simply not predictable or visible. Here are described some examples of cracking of one hydraulic piston, when all the parameters of mechanical or chemical requirements are satisfied at the moment of production, but in spite of this, the piston failed in servicing.

Such discontinuities could not be explained by regular working conditions of a hydraulic component, but just from the point of view of quality of the forged and heat treated product.

Melting and refining regimes, also forging, are responsible for obtaining those irregularities on the surface just near the square part of the forged connecting rod, but machining (either turning or milling) operations cannot be responsible for detected faults.

A sketch of connecting rod and places for replica R1 and R2 monitoring are shown in Fig. 2.

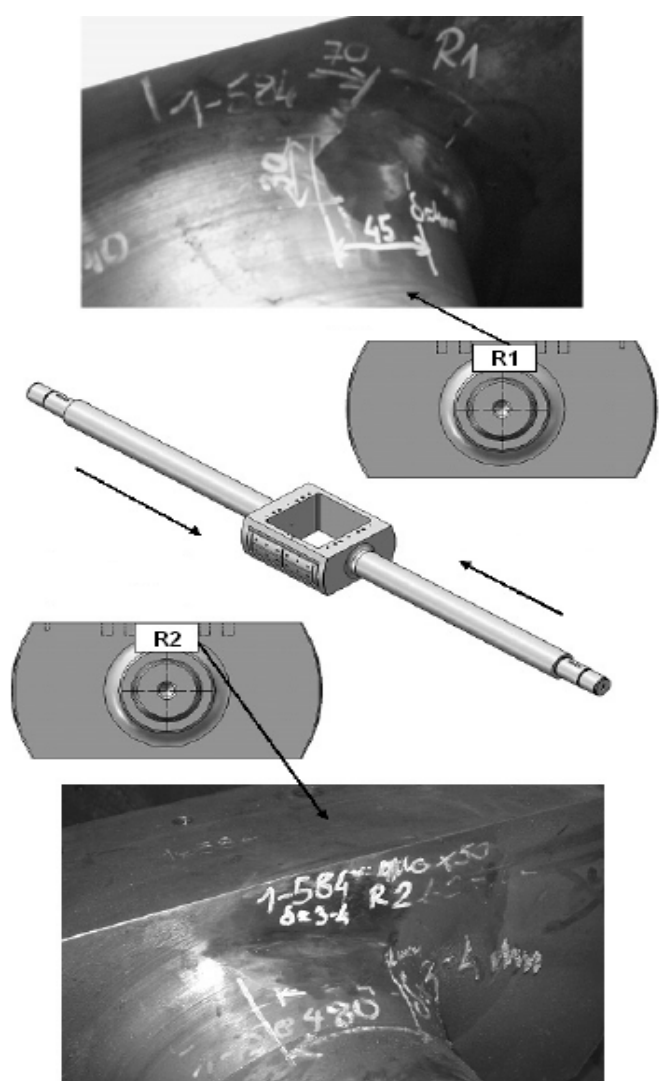

Fig. 2. Sketch of connecting rod and places for replica monitoring 
In the areas where replicas $\mathrm{R} 1$ and $\mathrm{R} 2$ were taken, there were also determined chemical composition and hardness measurements.

The microstructure of the investigated material (Fig. 3) before exploitation consists of ferrite and pearlite, with small non-metallic inclusions.

The changes in the microstructure of connecting rod material must be also of great importance. Those processes are: decarburization, corrosion, micro- and macro-cracks, etc.

A wide variety of degradation processes are possible to discover with the use of replica metallography.

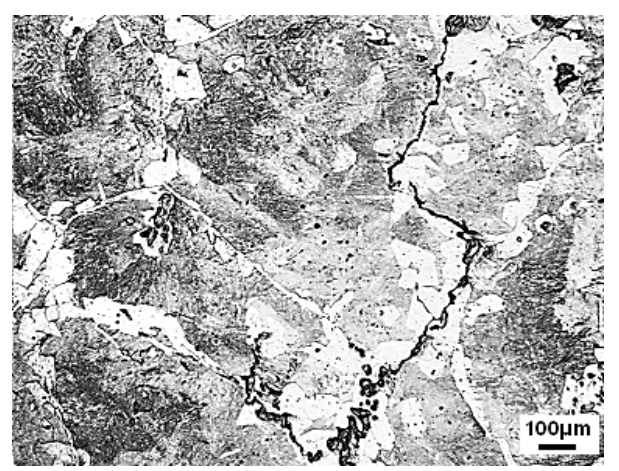

Fig. 3. The microstructure consists of ferrite, pearlite and some bainite. Micro- and macro cracks observed under optical microscope. $4 \%$ natal

\section{Conclusion}

The role of the connecting rod in a hydropower plant is of great importance.

The NDM techniques offer a possibility of detecting materials damage at an early stage and thus prevent dangerous and costly failures.

Plants that are notoriously exposed to gradual degradation will be safer and live longer if areas of the highest degradation rate are located and possible damage repaired at an early stage.
The changes in the microstructure of the connecting rod material must also be of great importance. A wide variety of degradation processes are possible to discover with the use of replica metallography. Those processes are: decarburization, corrosion, micro- and macrocracks, etc.

The above results led to a direct recovery of the connecting rod of the water turbines in the area of identified macro-cracks, and after repeated tests, it was determined that it was not necessary to replace it.

\section{References}

[1] ASM HANDBOOK. 1989. Volume 9. Metallography and Microstructure. ASM Handbook Committee. 1989.

[2] ASM HandBOOK. 1989. Volume 11. Failure analysis and prevention. ASM Handbook Committee. 1989.

[3] ASM HandBook. 1989. Volume 17. Nondestructive Evaluation and Quality Control. ASM Handbook Committee. 1989.

[4] "Emergency Standard Practice for Production and Evaluation of Field Metallographic Replicas", ASTM ES-12-87.

[5] KeHL G.L., 1949. The Principles of Metallographic Laboratory Practice, 3rd Ed. 1949.

[6] Kovačević Z., Karastojković Z., Janjušević Z. 2009. Characteristic changes in microstructure of steel ČSN 15223.9 from boiler drum at power station monitored by replica method. Mining and Metallurgy Institute. Bor. 2009. 41th International October Conference on Mining and Metallurgy. Kladovo 2009

[7] "NDT-Metallographic Replica Techniques of Surface Examinations". ISO 3057-1974.

[8] Neubuer B. \& Wedel U. 1994. NDT Replication Avoids Unnecessary Replacement of Power Plant Components. Power Engineering. 1994.

[9] VAnder Vort G.F. 1984. Metallography: Principles and Practice. McGraw-Hill. 